\title{
CUA - Listening and learning how to best serve the urology community!
}

Fred Saad, MD, FRCS

\section{CUA President}

Cite as: Can Urol Assoc J 2019;13(4):81.

http://dx.doi.org/10.5489/cuaj.5953

Pour la version française, voir cuaj.ca

The CUA exists to promote the highest standard of urologic care for Canadians and to advance the art and science of urology.
S pring is just around the corner and our Canadian hibernation will soon come to an end! Importantly, that means we are now in full gear to put the final touches on the CUA annual meeting and I look forward to seeing all of you in Quebec City June 29 to July 1 . The meeting is lined up to be scientifically stimulating, while providing ample opportunity to catch up with colleagues and friends. The CUA annual meeting is also where new friendships and collaborations often start. In a beautiful setting, with great social events and an outstanding scientific meeting, we are certain that all those attending will leave with new practice-changing knowledge and great memories!

This year is also one that includes an opportunity to review how well the CUA has done since our last five-year strategic plan, as well as to prepare a new plan moving forward. Front and centre in our next plan: how to continue to improve what we do and remain relevant to all our members, both in the community and academic settings. Although the vast majority of urologists in Canada are members of the CUA, we have made it a priority to understand why some choose not to be members. Focus groups, held in several cities across Canada, have been invaluable and have allowed us to listen and learn. Many in attendance were actually surprised to learn just how much CUA has to offer! Communication appears to be key, and with such a large country and extremely busy urologists, we at the CUA have to innovate to reach out and inform. From our hugely popular patient information booklets, to all the educational activities and research grants provided, we are proud of what we are doing and want to continue to do more.

The CUA has taken on the leadership role in all aspects of urology, as well as a leadership role in other specialties dealing with urological issues. With leadership comes responsibility, and we take this very seriously. We encourage all urologists, as well as non-urologists dealing with patients affected by urological conditions to reach out and make suggestions or verbalize their needs. On our end, we will do all we can to address those needs and seriously consider all your suggestions. 